\title{
Analisis inovasi produk pada ekonomi kreatif sektor kerajinan galeri Batik Tabir Riau di Kota Pekanbaru
}

\author{
Shafira Amalia Ramadhani ${ }^{1^{*}}$ \\ ${ }^{1}$ Universitas Riau \\ *Correspondent email : shafiraamaliaramadhani15@gmail.com
}

\begin{abstract}
This research aims to increase creative economy competitiveness in Pekanbaru city specifically for batik craft sub-sector. This research was conducted with descriptive and quantitative methods, reffering to Galeri Batik Tabir Riau Rani's product innovation. The research data is composed of primary and secondary data. To obtain primary data, researcher uses observations, focused discussion and interview methods, and for the secondary data refers to Central Agency on Statistics Indonesia, literature books, journals, and internet. From the questionnaire data and focused discussion process, this research can be conclude that using SO strategy, that is utilize the power of opportunity, can increase economy competitiveness on Galeri Batik Tabir Riau Rani.
\end{abstract}

Keywords: Product Innovation; creative economy

\section{PENDAHULUAN}

Permintaan akan pemenuhan kebutuhan saat ini terus meningkat, hal tersebut mendorong para pelaku bisnis untuk terus berupaya memenuhi segala kebutuhan konsumen melalui ide dan inovasi baru untuk menghasilkan beragam produk. Usaha yang dilakukan diantaranya yaitu memanfaatkan teknologi dan membentuk gagasan-gagasan baru untuk menciptakan sebuah produk baru.

Kemajuan teknologi memberikan pengaruh positif kepada para pelaku ekonomi. Melalui teknologi, kelangkaan suatu produk karena permintaan akan produk tersebut semakin meningkat bisa dihindari. Melalui teknologi yang menjadi alat untuk manusia berinovasi, kini mampu menghadirkan produk alternatif untuk memenuhi kebutuhan akan sebuah produk, baik barang maupun jasa.

Perubahan zaman, menyebabkan gaya hidup terus berubah dan semakin modern, termasuk perubahan disektor ekonomi, seperti pola produksi, distribusi, dan konsumsi yang berubah kearah yang diinginkan oleh masyarakat. Saat ini juga kita ketahui bersama bahwa kegiatan ekonomi jauh lebih mudah dan efisien dengan munculnya kegiatan ekonomi berbasis teknologi dan ilmu pengetahuan. Belakangan ini, sering kita temukan usaha yang mengolah bahan baku dengan memadukannya dengan ide-ide baru yang mereka dapatkan melalukan kreativitas, teknologi, dan informasi menjadi sesuatu yang bernilai jual tinggi yang kita kenal dengan ekonomi kreatif.

Pengembangan industri kreatif diyakini dapat memberi warna baru bagi sektor ekonomi dan pembangunan Negara. Industri dengan pola kreativitas ini terus di galakkan dan dikembangkan dengan bantuan para cendikiawan, pemerintah dan pelaku usaha industri kreatif itu sendiri.

Berdasarkan hasil pemetaan potensi ekonomi kreatif yang dilakukan oleh Badan Ekonomi Kreatif Indonesia tahun 2016, ada 16 subsektor ekonomi kreatif yang terdiri dari: Aplikasi dan pengembangan game, Periklanan, Penerbitan, Pasar barang seni, Kerajinan, Desain, Fashion, Video, Film, dan Fotografi, Musik, Seni pertunjukan, Kuliner, Televisi dan radio, Layanan computer dan piranti lunak, Riset pengembangan, dan Arsitektur. (Badan Ekonomi Kreatif Nasional, 2018)

Pemerintah provinsi Riau tengah fokus mengembangkan ekonomi kreatif yang dipahami memiliki dampak yang sangat baik bagi perekonomian. Hal ini mengacu pada keinginan Pemerintah Pusat melalui instruksi Presiden Nomor 6 Tahun. Kontribusi sector ekonomi kreatif terhadap Produk Domestik Bruto (PDB) mencapai 1.105 triliun di tahun 2017, sumbangan PDB ekonomi kreatif terhadap PDB nasional tahun 2017 mencapai 7,57\% (Badan Ekonomi Kreatif Nasional, 2018). Dari 16 subsector ekonomi kreatif, terdapat tiga subsector yang memberikan kontribusi dominan terhadap PDB, yaitu kuliner sebesar 32,5\%, fashion sebesar 28,3\%, dan kerajinan sebesar 14,4\% (Kamar dagang dan Industri, 2018). Pada Riau sendiri berdasarkan informasi yang didapatkan dari kepala bidang Ekonomi Kreatif Dinas Pariwisata 
Provinsi Riau, saat ini Riau terkhususnya Pekanbaru tengah menggalakkan ekonomi kreatif pada dua sub sector yaitu kerajinan (kriya) dan kuliner, dibuktikan melalui kegiatan "Riau Street Fiesta" yang mencoba menampilkan kriya unik dan kuliner yang inovatif.

Kebudayaan yang dimiliki Provinsi Riau sangat beragam, diantaranya yaitu Batik Riau yng menjadi ciri khas Budaya Melayu dan merupakan kearifan budaya lokal, kearifan lokal adalah jawaban kreatif terhadap situasi geografis-politis, historis, dan situasional yang bersifat lokal yang mengandung sikap, pandangan, dan kemampuan suatu masyarakat (Setiawan,2014). Saat ini Batik Riau mulai dilirik dan diminati oleh masyarakat luas, dan mulai digunakan oleh masyarakat umum serta kaula muda, namun eksistensi Batik Riau masih kalah dengan batik dari daerah lain seperti Batik Pekalongan, Batik Jogja, Batik Solo dan jenis batik lain dari daerah pulau Jawa.

Galeri Batik Tabir Riau Rani sebagai pelopor batik Riau modern di Kota Pekanbaru, memiliki variasi produk yang beragam, diantaranya yaitu, produk kaftan, baju jadi pria dan wanita, kain meteran berbagai jenis bahan dari katun dobby, katun marimis, klasik, sarimbit dobby,sarimbit fiskos,fiskos,dan kain dengan bahan berseller dan produk termahalnya adalah kain berbahan sarimbit sutera baron, produk lainnya yaitu sarung, jilbab, dan sajadah. Galeri Batik Tabir Riau banyak melakukan inovasi terhadap varian produknya, hampir berbagai jenis barang dengan berbahan dasar batik Riau tersedia disini.

Inovasi produk yang dilakukan oleh Galeri Batik Tabir Riau sesuai dengan pendapat (Suryana,2012) tentang inovasi produk, yaitu pelaku usaha dapat melakukan inovasi terhadap produknya agar produknya dapat dikenal oleh konsumen.

\section{METODE PENELITIAN}

Metode yang digunakan dalam penelitian ini adalah metode kualitatif dengan tipe deskriptif. Metode kualitatif adalah metode yang digunakan untuk meneliti pada kondisi objek yang alamiah yang menggunakan instrument kunci (Sugiyono, 2016:9).

\section{Subjek Penelitian}

Riset kualitatif tidak mencoba untuk membuat generalisasi terhadap hasil. Kualitatif lebih bersifat kontekstual saat riset sedang dilakukan (Sugiyono,2017). Sampel pada penenlitian kualitatif disebut sebagai informan (subjek penelitian). Informan yang menjadi subjek pada penelitian ini ada 2 orang yang tediri atas pemilik Usaha Galeri Batik Tabir Riau sebagai key informan dan kapten toko sebagai informan.

\section{Teknik Pengumpulan Data}

Dalam pengumpulan data, peneliti menggunakan teknik pengumpulan data sebagai berikut:

\section{Observasi}

Menurut Hadi (dalam Sugiyono 2012;145) observasi merupakan suatu proses kompleks, suatu proses yang tersusun dari berbagai proses biologis dan psikologi. Teknik ini digunakan bila penelitian berkenaan dengan perilaku manusia, proses kerja, gejala-gejala alam dan bila responden yang diamati tidak terlalu besar. Observasi dilakukan dengan pengamatan langsung terhadap proses-proses yang dilakukan dilapangan. Dalam hal ini penulis melihat langsung dan mengamati pelaku usaha Batik Tabir Riau Rani dan para konsumen Batik Tabir Riau Rani, peristiwa, tempat, dan lokasi kemudian melakukan pencatatan-pencatatan mengenai objek yang diteliti.

\section{Wawancara}

Teknik pengumpulan data dengan cara melakukan tanya jawab oleh peneliti kepada responden. Teknik ini dilakukan agar informasi yang didapatkan oleh peneliti lebih jelas dan akurat serta mandalam. Teknik ini juga bermanfaat jika diterapkan kepada informan yang dianggap banyak tahu tentang apa yang sedang diteliti (Sugiyono,2008).

\section{Dokumentasi}

Dokumentasi merupakan catatan peristiwa yang sudah berlalu. Dokumen bisa berbentuk gambar, tulisan, atau karya dari seseorang. Contoh dokumen yang berbentuk tulisan adalah biografi, sejarah, kebijakan. Sedangkan dokumen yang berbentuk gambar seperti foto, sketsa, dan gambar. Dokumentasi dan arsip merupakan sumber data penting karena mengingat penelitian ini juga berhubungan dengan latar belakang peristiwa yang telah terjadi yang berkaitan dengan kondisi saat sekarang ini. 


\section{Studi Kepustakaan}

Studi kepustakaan merupakan cara yang dilakukan untuk mengumpulkan data dan informasi melalui berbagai literature yang berhubungan dengan penelitian ini. Data dan informasi dapat diperoleh melalui buku-buku, internet, jurnal, tesis, serta skripsi.

\section{HASIL DAN PEMBAHASAN}

Identitas key informan dan informan merupakan keterangan yang diperoleh dari wawancara yang dilakukan oleh penulis yang berisikan mengenai nama, umur, jenis kelamin, dan pendidikan terakhir dari ker informan dan informan, untuk lebih jelasnya mengenai key informan dan informan maka dapat dilihat pada keterangan dbawah ini sebagai berikut:

Tabel 1. Identitas Key Informan Dan Informan

\begin{tabular}{|c|c|c|c|c|c|c|}
\hline \multirow[t]{2}{*}{ No } & \multirow[t]{2}{*}{ Key Informan dan Informan } & \multirow[t]{2}{*}{$\begin{array}{l}\text { Umur } \\
\text { (Tahun) }\end{array}$} & \multirow[t]{2}{*}{$\begin{array}{c}\text { Tingkat } \\
\text { Pendidikan }\end{array}$} & \multicolumn{2}{|c|}{$\begin{array}{c}\text { Jenis } \\
\text { Kelamin } \\
\end{array}$} & \multirow[t]{2}{*}{$\begin{array}{l}\text { Jum } \\
\text { lah }\end{array}$} \\
\hline & & & & $\bar{L}$ & $\mathrm{P}$ & \\
\hline 1. & $\begin{array}{l}\text { Pemilik Usaha Galeri Batik } \\
\text { Tabir Riau Rani }\end{array}$ & 49 & SARJANA & - & 1 & 1 \\
\hline 2 & Kapten Toko & $\mathrm{AH}^{50}$ & SARJANA & $\begin{array}{l}1 \\
1\end{array}$ & 1 & $\begin{array}{l}1 \\
2\end{array}$ \\
\hline
\end{tabular}

Setiap orang yang melakukan usaha pasti akan melakukan modifikasi terhadap produknya agar produk yang dihasilkan oleh perusahaan, ataupun UMKM terus berkembang, sejalan dengan tujuan inovasi yaitu untuk membuat sebuah produk atau jasa dengan jenis yang baru. Tetapi bukan hanya untuk mengasilkan produk dengan jenis yang baru, namun juga dapat menjadi proses peningkatan nilai (value) dan pengembangan dari sebuah produk yang sudah beredar, sehingga inovasi menjadi salah satu sumber energi dalam keunggulan bersaing berdasarkan pada kreativitas yang didapatkan melalui proses pengelolaan, dan inovasi dianggap fungsi penting dari bisnis setelah pemasaran. Daya saing diidentikkan dengan produktivitas dimana tingkat output yang dihasilkan untuk setiap unit input yang digunakan (Porter, 2007).

\section{Analisis Pasar}

Analisis pasar adalah proses penilaian dan pengkajian suatu situasi pasar untuk menunjang suatu kegiatan pemasaran (Anindita,2017). Berikut hasil wawancara peneliti mengenai beberapa aspek yang menjadi sub indictor dalam analisis pasar untuk melihat daya saing suatu produk :

\section{Jenis dan Sifat Barang}

Berdasarkan hasil wawancara diatas dapat disimpulkan bahwa Galeri Batik Tabir Riau Rani tidak hanya menjual produk yang siap pakai seperi baju, jilbab, sajadah, tetapi juga menjual produk lain seperti kain 2,5 meter

\section{Kuantitas dan Kualitas Barang}

Setiap produk memiliki kuantitas dan sebuah kualitas yang menjadi keunggulan untuk produk tersebut, serta menjadi pembeda antara produk tersebut dengan produk yang lainnya.(Isventina,2015). Berdasarkan hasil wawancara diatas, dapat kita pahami Galeri Batik Tabir Riau Rani memiliki kualitas yang sangat baik jika dilihat dari produk yang di pasarkan, dalam hal kuantitas mereka selalu menjaga dengan mengendalikan proses produksi.

\section{Warna dan Ukuran}

Warna sebuah produk menjadi sebuah penilaian visual yang kasat oleh mata, warna menjadi suatu aspek penting dalam meningkatkan ketertarikan seorang konsumen terhadap sebuah produk. (Prianti, 2015). Berdasarkan hasil wawancara diatas dengan pemilik Galeri Batik Tabir Riau Rani kita simpulkan bahwa mereka sadar betul akan pentingnya melakukan survey keadaan pasar terkait selera konsumen, khususnya tentang pemilihan warna, agar produk yang ditawarkan sesuai dengan keinginan pasar. 


\section{Desain dan Model Barang}

Berdasarkan hasil wawancara diatas, disimpulkan bahwa Galeri Batik Tabir Riau Rani selalu mengutamakan kebutuhan dan keinginan konsumen secara luas, terlihat dari produk-produk yang didesain sesuai trend fashion saat itu.

\section{Merk dan Harga Barang}

Merek sebuah produk menjadi penguat suatu produk yang dipasarkan, karena semakin kuat merek sebuah produk, maka semakin mudah perusahaan tersebut untuk memimpin pasar dan mengalahkan pesaing-pesaing sejenis di pasaran, merek juga merupakan sebuah identitas suatu produk dan menjadi pembeda antara produk yang satu dengan yang lainnya (Saptana,2010). Sementara harga adalah sebuah unsur yang menjadi penentu tinggi rendahnya permintaan terhadap prduk tersebut. (Tjiptono, dalam Polnaya \& Darwanto,2015). Berdasarkan hasil wawancara diatas dapat disimpulkan bahwa Galeri Batik Tabir Riau Rani merupakan merek batik Riau yang sudah dikenal oleh khalayak ramai, dan harga yang ditawarkan juga tidak main-main, Galeri Batik Tabir Riau Rani menjual batik Riau dengan harga yang cukup tinggi.

\section{Analisis Kompetitor}

Analisis kompetitor merupakan penilaian yang dilakukan untuk melihat keadaan pesaing agar perusahaan atau usaha tidak kalah dengan pesaing yang ada (Saptana,2010).

\section{Produk Pesaing}

Berdasarkan hasil wawancara diatas dapat disimpulkan, Galeri Batik Tabir Riau Rani merasa produk dari pesaing mampu memacu untuk terus lebih baik lagi, dan mereka tidak pernah merasa pesaing menjadi penghambat jalan mereka

\section{Pasar Pesaing}

Berdasarkan hasil wawancara diatas, disimpulkan bahwa pasar pesaing yang harus dikuasai sama dengan pasar yang dimiliki Galeri Batik Tabir Riau Rani.

\section{Keunggulan dan Kelemahan Pesaing}

Berdasarkan hasil wawancara diatas, dapat disimpulkan bahwa Galeri Batik Tabir Riau Rani selalu menjaga hubungan baik dengan para pemasok kebutuhan bahan bakunya, melalui menciptakan rasa kepercayaan diantara setiap pemasoknya, dari berdirinya Galeri Batik Tabir Riau Rani hingga saat ini mereka masih setia dengan industry-industri langganan.

\section{Analisis Pemasok}

Pemasok adalah kelompok baik perusahaan maupun perorangan yang mampu menyeiakan kebutuhan pokok sebuah perusahaan atau perorangan lainnya.(Porter,1998)

\section{Pengembangan Produk}

Berdasarkan hasil wawancara diatas, pengembangan produk dilakukan oleh pemasok yang dalam hal ini adalah pabrik Galeri Batik Tabir Riau Rani dan penyedia bahan baku batik pengembangan dilakukan berdasarkan intruksi dan keinginan dan pemilik Galeri Batik Tabir Riau Rani.

\section{Pengadaan}

Berdasarkan hasil wawancara diatas dapat disimpulkan bahwa Galeri Batik Tabir Riau Rani melakukan pengadaan secara berkala setiap bulannya.

\section{Perencanaan dan Pengendalian}

Berdasarkan wawancara mengenai perencanaan dan pengendalian produk Galeri Batik Tabir Riau Rani melakukannya sesuai dengan kebutuhan toko.

\section{Pengiriman dan Distribusi}

Berdasarkan hasil wawancara terkait analisis pemasok di dapati bahwa Galeri Batik Tabir Riau Rani menjalin komunikasi yang baik dengan pemasok dan selalu berkoordinasi dalam seluruh aktivitas produksi dan pemenuhan bahan baku. 
Berdasarkan hasil wawancara yang penulis lakukan kepada key informan dan informan, Galeri Batik Tabir Riau memiliki kualitas yang baik, hal tersebut dapat dilihat dari ketahanan produk, produk kerajinan batik ini tidak akan luntur saat dicuci, dan warnanya juga akan bertahan.

\section{KESIMPULAN}

Dapat disimpulkan, bahwa Galeri Batik Tabir Riau memiliki daya saing yang baik, ditinjau dari analisis pasar, pesaing,dan pemasok yang ada pada Galeri Batik Tabir Riau Rani. Batik Riau yang selamam ini terkesan norak dan bernuansa sangat tradisional, berhasil di ubah sedemikian rupa desain dan tampilannya menjadi lebih modern dan semakin diminati oleh konsumen.

\section{UCAPAN TERIMAKASIH}

Terimakasih kepada Galeri Batik Tabir Riau Rani yang telah membantu secara kooperatif dalam menyelesaikan karya ini Terimakasih kepada Dinas Pariwisata \& Ekonomi Kreatif Provinsi Riau Terimakasih kepada Kamar Dagang \& Industri Provinsi Riau Karya ini didukung oleh Universitas Islam Riau dan Universitas Riau

\section{DAFTAR PUSTAKA}

Anindita, Wicaksono, \& Maulidah. (2017). Analisis Daya Saing Komoditas Bawang Merah di Kabupaten Kediri, Jurnal Ekonomi Pertanian dan Agribisnis, Vol. 1, No. 1.

Badan Ekonomi Kreatif Nasional (2018),.Sub Sektor Ekonomi Kreatif di Indonesia, Jakarta.

Badan Ekonomi Kreatif Nasional. (2018). Kontribusi Ekonomi Kreatif bagi PDB Negara, Jakarta.

Isventina. (2015). Analisis Daya Saing Sektor Industri Prioritas Indonesia Dalam Menghadapi Pasar ASEAN, Jurnal Ekonomi dan Kebijakan Pembangunan, Vol. 4, No.1.

Kamar Dagang \& Industri Provinsi Riau. (2018). Sub Sektor Ekonomi Kreaatif Penyumbang PDB Terbesar, Pekanbaru.

nasu

Polnaya \& Darwanto. (2015). Pengembangan Ekonomi Lokal Untuk Meningkatkan Daya Saing Pada UKM Ekonomi Kreatif Batik Bakaran di Pati, Jawa Tengah, Vol. 22, No. 1.

Prianti, P., Nasution, I.G.S. (2015). Analisis Daya Saing Ekonomi di Kabupaten Labuhanbatu Selatan, Jurnal Ekonomi dan Keuangan, Vol. 3, No. 6.

Porter, E Michael (2007). Strategi Bersaing (competitive strategy) Teknik Menganalisis Industry Dan Pesaing, Tangerang: KARISMA Publishing Group.

Porter, Michael.(1998). The Free Press,USA, Competitive Strategy.

Saptana, 2010, Tinjauan Konseptual Mikro-Makro Daya Saing Dan Strategi.

Setiawan, Hartono, dan Suryantini. (2014). Analisis Daya Saing Komoditas Kelapa di Kabupaten Kupang, Jurnal Agritech, Vol. 34, No.1.

Sugiyono. (2008). Metode Penelitian Kuantitatif, Kualitatif dan R\&G, Bandung : Penerbit Alfabet.

Sugiyono. (2016). Metode Penelitian Kuantitatif, Kualitatif dan R\&D. Bandung:Alfabeta.

Sugiyono. (2012). Metode Penelitian Kuantitatif Kualitatif dan R\&B. Bandung: Alfabeta.

Sugiyono. (2017). Metode Penelitian Kualitatif, Yogyakarta : Penerbit Alpabet

Suryana. (2012). Ekonomi Kreatif, Bandung:Salemba Empat. 